\title{
Representaciones de infancia en Frankenstein de Mary Shelley: De la edad de oro a la niñez monstruosa'
}

\author{
Representations of Childhood in Mary Shelley's Frankenstein: \\ From the Golden Years to Monstrous Childhood
}

\author{
MARÍA AYELÉN BAYERQUE \\ Universidad Nacional de Mar del Plata \\ Argentina \\ mabayerque@gmail.com
}

(Recibido: 23-O3-202O; aceptado: $05^{-\mathrm{II}-2 \mathrm{O} 2 \mathrm{I})}$

Resumen. En este trabajo se analizan diferentes representaciones de infancia presentes en Frankenstein de Mary Shelley. Para esto, se han dispuesto tres apartados. En primer lugar situaremos a la novela en su contexto de producción, para luego analizar algunos elementos de la concepción romántica sobre la primera parte de la vida. Alzate Piedrahíta (2002) entiende que la percepción de la infancia moderna ha variado a lo largo de la historia en función de cambios ocurridos en los modos de socialización. Si pensamos que en Frankenstein la niñez tiene dos frentes, el humano y el monstruoso, nos preguntamos icómo se vincula esta cuestión con la matriz romántica que opera en el texto? En un segundo apartado, a través del análisis textual de algunos fragmentos, se compara la niñez del protagonista y de su hermana adoptiva, Elizabeth. Por último, se aborda a la criatura y su vínculo con el personaje que lo ha creado. Luego de su nacimiento se comporta como cualquier niño que imita lo que hacen otros y que se encuentra perdido sin un tutor que lo guíe.

Palabras clave: infancia; juventud; novela; representación mental; educación.
Abstract. In this paper different representations of childhood in Mary Shelley's Frankenstein are analyzed. For this, three sections have been arranged. First, the novel is set in the context of its production, and then some elements of the romanticized vision of the first part of human's lives are analyzed. Alzate Piedrahíta (2002) understands that the perception of modern childhood has varied throughout history based on changes in the modes of socialization. If thinking childhood has two fronts, the human and the monstrous in Frankenstein, how does this question link with the romantic matrix that operates in the text? In the second section, through the textual analysis of some fragments, the childhood of the protagonist and his adoptive sister, Elizabeth, are compared. Finally, the creature and his link to the character that created him are studied.After his birth, he behaves like any child who imitates what others do, and finds himself lost without a tutor to guide him.

Keywords: childhood; youth; novel; visualization; education.

\footnotetext{
${ }^{\text {I }}$ Para citar este artículo: Ayelén Bayerque, María (2O2I). Representaciones de infancia en Frankenstein de Mary Shelley: De la edad de oro a la niñez monstruosa. Alabe 24 . [www.revistaalabe.com] DOI: IO.I5645/Alabe2O2I.24.I
} 
Libramos nuestra lucha por la responsabilidad contra un enmascarado.

La máscara del adulto se llama “experiencia”. Es inexpresiva, impenetrable, siempre igual; ese adulto ya lo ha experimentado todo: la juventud, los ideales, las esperanzas, la mujer. Todo era ilusión. A menudo nos sentimos intimidados o amargados. Quizás ese adulto tenga razón. ¿Qué podemos contestarle? Nosotros aún no hemos experimentado nada.

Walter Benjamin

El propósito de este trabajo es analizar las representaciones de infancia en Frankenstein de Mary Shelley. Alzate Piedrahíta (2002) entiende que la percepción de la infancia moderna ha variado a lo largo de la historia en función de cambios ocurridos en los modos de socialización. Afirmamos que en la novela objeto de nuestro análisis, y especialmente en sus personajes, se reflejan las ideas románticas acerca de la infancia, así como también sus límites. Para respaldar esta aseveración, primero reconstruiremos el contexto de producción del texto literario, así como también la figura de autora de Mary Shelley. En un segundo apartado, analizaremos los personajes de Elizabeth y Víctor, por un lado, y su encarnación de la concepción romántica de infancia, la edad de oro de la vida, pura e idealizada que, sin embargo, presenta algunas fisuras. Por último, nos detendremos en la figura de la criatura, cuya infancia se distancia fuertemente de la de los personajes humanos y se caracteriza por ser una experiencia de confusión, dolor y soledad.

\section{Punto de partida: Mary Shelley, romántica inglesa}

Mary Shelley nace en I797, por lo que crece y se desarrolla en la primera parte del siglo XIX, un momento de numerosos cambios sociales, culturales y económicos tal como sostiene Vítor Manuel Aguiar y Silva (1982) en su clásico Teoría de la Literatura. El desarrollo del Romanticismo se ve influido por la difusión de la imprenta y el vertiginoso crecimiento de la industria editorial, así como también del periodismo y la novela por entregas. Las modificaciones en los consumos culturales y en la esfera de lo social transforman la función de la literatura, que muta para siempre luego de la segunda mitad del siglo XVIII. En esta época, circulan una serie de ideas provenientes de diversos campos. Algunas de ellas surgen como fruto de la Revolución francesa (I789). La época ilustrada, en la que la educación encabeza una cruzada pedagógica, se asocia con el surgimiento de la burguesía y modifica así el rol de la monarquía, única clase con acceso a la enseñanza sistemática hasta el momento. Por otra parte, ya en el Renacimiento se rompe con el con- 
cepto de autoridad medieval, lo que lleva a un auge de ciencias experimentales y filosóficas que se acrecentará en el siglo XIX. Por su lado, el Humanitarismo buscó la felicidad en la vida del hombre y el Liberalismo como ideología política se orienta a garantizar la libertad del individuo. De estos cimientos ideológicos diversos y heterogéneos nace el Romanticismo.

No es correcto nombrar al Romanticismo en singular, sino en plural, ya que puede dividirse en varias etapas, históricamente, y tiene ciertas particularidades en función del lugar geográfico sobre el que nos interese detenernos. Nos ocuparemos, en este caso, del Romanticismo inglés, aunque sin duda, hay algunos elementos que permiten unificar a este movimiento europeo. Es, de hecho, la primera poética internacional, ya que más allá de las diferencias, se manifiesta en la literatura de gran cantidad de países al mismo tiempo. Como sostiene Peckam (I962) en la época romántica existe un cambio social, un colapso explicativo. El arte se vuelve una respuesta a las preguntas que la religión ya no puede responder. Lo privado de cada sujeto se separa del resto de las relaciones sociales y nace la familia nuclear que rompe con la familia feudal extendida. Por lo antes dicho, toma forma la intimidad moderna. Estos elementos son la base del liberalismo económico y la propiedad privada. El yo comienza a definirse por sus deseos, no por sus posesiones. El sujeto, que en el Neoclasicismo estética predominante previamente, había estado dominado por la razón y el equilibrio, en el Romanticismo pasa a replegarse sobre sí mismo para analizarse. Por esta valoración del yo, se hace énfasis en la originalidad, resurge la idea del genio creador, y el proceso de invención cobra preponderancia. En esta división, el ser íntimo se valora por sobre la razón (Aguiar e Silvia, I982).

Por otra parte, el Romanticismo es el primer movimiento estético que se relaciona con la fantasía. El mapa psíquico del psicoanálisis complementa y vincula la presencia de lo sobrenatural directamente con la escisión del sujeto. En Frankenstein, los elementos propios de la novela gótica también se asientan en esta nueva forma de concebir al individuo. Según Amícola (2003), "la ficción gótica (...) va a estar sustentada por un resquebrajamiento en certidumbres epistemológicas conectadas con el comienzo de la ruptura de la unidad de conciencia” (49). Se genera así un espacio para la fantasía y los elementos sobrenaturales en la ficción que muchas veces se relaciona con la necesidad de evasión del presente, un sentimiento nostálgico del pasado como lugar mejor (Aguiar e Silvia, I982).

En este contexto europeo y romántico nace Mary Shelley (I797-I85I). Sus padres fueron el filósofo William Godwin -más tarde reconocido como fuente del pensamiento comunista y anarquista-y la escritora y feminista Mary Wollstonecraft-quien interpretó la usurpación de las propiedades a mujeres en las novelas góticas era signo de un mundo laberíntico lleno de amenazas para ellas (Amícola, 2003)-. Si bien, como hemos comentado en párrafos anteriores, los ideales ilustrados de la Revolución Francesa incluyen la difusión de la educación junto a otros derechos del hombre, estas nuevas facultades no alcanzan a las mujeres (Amícola, 2003: 40). La madre de Mary muere pocos días después de su nacimiento, Godwin vuelve a casarse y la educación de la pequeña -a diferencia de 
la de sus medios hermanos varones que fueron enviados a escuelas de prestigio- queda supeditada a la enseñanza de la lectura por parte de su niñera, sumado a algunas lecciones de música. Sin embargo, una lista de lecturas elaborada por su padre y tener a su disposición su biblioteca abre la puerta a una formación literaria (Burdiel, r999). Muy joven todavía, en mayo de I8ı4, Mary conoce a Percy Shelley y dos meses más tarde abandona Inglaterra con él. En ı8ı6, la primera esposa de Shelley, que los acompaña en sus viajes, se suicida y los enamorados se casan. Shelley era cinco años mayor que su mujer y se había acercado a su familia por el interés en las ideas anarquistas del padre de Mary, que alimentaban también su concepción de amor libre (Burdiel, I999). Como es sabido, es muy reconocido en su época como poeta.

En I8I8 se publica la primera edición de Frankenstein o el moderno Prometeo, pero es recién en I83I cuando la autora revisa la obra y escribe una introducción que aporta muchos datos acerca de cómo surge el texto. Según la propia Mary (Shelley, 2008) su interés por la escritura se origina en su infancia y en el oficio de sus padres. En esas mismas palabras iniciales, cuenta que, en el verano de i8I6, con su marido y su hermana, visitan a su amigo Lord Byron en Suiza. Si bien no lo recupera en el prólogo, en ese momento ella estaba embarazada de un hijo que moriría siendo muy pequeño -lo que se convertiría en una constante en la vida del matrimonio Shelley, la pérdida de niños con nacimientos prematuros o en la primera infancia-. El mal clima los obliga a permanecer mucho tiempo dentro del caserón en el que se alojaban y empiezan a leer historias de fantasmas. Por el interés que les suscita la lectura, Byron propone que cada uno escriba una. Según Mary, el objetivo era lograr "Una historia que hablase de los misteriosos temores de nuestra naturaleza y despertase un horror excitante, que hiciese que los lectores temieran mirar a su alrededor, les helase la sangre, les acelerase los latidos del corazón” (Shelley, 2008: Io). A la estimulante propuesta de Byron, se suma una conversación que Mary escucha entre su marido y el dueño de casa. Los hombres charlan acerca de la posibilidad de reanimar un cuerpo, de fabricar las partes de una criatura, colocarlas juntas y dotarlas de vida. Estas ideas circulaban en la época, incluso Byron y Shelley citaban a Erasmus Darwin, abuelo del naturalista que más tarde desarrollaría la teoría de la evolución, como exponente principal del galvanismo. Esa noche, Mary sueña con la criatura y a partir de ese discurrir onírico comienza con la escritura de la novela.

La inclusión de la conocida anécdota en este trabajo no es casual. Se presenta como un buen punto de partida para pensar en el Romanticismo y la novela, ya que los sujetos que forman parte de esa velada han sido exponentes fundamentales del movimiento. A partir del desafío planteado, surge un texto que recupera un resto diurno y la inquietud que le genera a Shelley lo oculto del ser humano, además del uso de la ciencia. Sin duda, un tema recurrente en la literatura fantástica y de ciencia ficción. Por otra parte, el gótico, iniciado por Horace Walpole, se desarrolla fuertemente a través de la escritura de mujeres, como Ann Radcliffe, gran exponente, o George Eliot (seudónimo de Mary Ann Evans) y hasta Jane Austen, a través de su parodia del género en Northanger Abbey. Ser escritora en los albores del siglo XIX implicó para Shelley un deseo de fama, pero tam- 
bién la certeza de que eso socavaría su imagen de mujer decente en la época, cuyo lugar natural era el ámbito privado, ser madre y esposa (Burdiel, I999).

Desde una perspectiva bourdiana (Bourdieu, I97I, I984, I995), la ubicación de la novela en el sistema de relaciones que componen el contexto y la reconstrucción de la figura de autora de Mary Shelley nos otorga un inicio necesario para el análisis de las representaciones de infancia en la novela. Más allá de las cuestiones biográficas mencionadas y si bien contaba con importantes antecedentes dentro del gótico, en Frankenstein Shelley logra superar este género incorporando también elementos de la novela de aprendizaje, la literatura fantástica y trabajar con el ideario romántico, sumado a numerosos elementos autobiográficos -que enumeran detalladamente autores como Burdiel (I999) o Gandolfo (2OI7) - . El contexto de producción, por otra parte, se vincula directamente con las representaciones de infancia que se entretejen en la novela: "La categoría de infancia es, en definitiva, una representación colectiva producto de las formas de cooperación entre grupos sociales también en pugna, de relaciones de fuerza, de estrategias de dominio. La categoría de infancia está orientada por intereses sociopolíticos” (Alzate Piedrahíta, 2002: 4). Para analizar las representaciones de infancia en la novela, nos concentraremos a continuación en dos personajes humanos, Víctor y Elizabeth, y uno sobrenatural, la criatura.

\section{La edad de oro}

La estructura de Frankenstein concuerda con la de un relato enmarcado. Una serie de cartas que Robert Walton envía a su hermana Margaret Saville encuadran los veinticuatro capítulos. Allí Robert le cuenta lo que está viviendo cerca del Polo Norte, en su expedición hacia tierras jamás divisadas por el hombre. Dentro de esa estructura, Víctor Frankenstein cuenta su propia historia a Walton, luego de que este último lo encuentre al borde de la hipotermia en un trineo. Como veremos, en estas cajas chinas se hallan siempre relatos de la propia vida, testimonios del ámbito de lo privado que cobran relevancia.

En primer lugar, analizaremos la voz del personaje protagonista, que le narra su vida a Walton. Víctor comienza el relato contando que nació en Ginebra, en una familia acomodada, ya que su padre poseía cargos públicos y propiedades. Sin embargo, va más allá. Con una cierta nostalgia del pasado perdido, como buen héroe romántico, su discurso sigue un orden cronológico: detalla que su padre recoge a su madre, hija de un amigo suyo que había muerto -y primera huérfana que aparece en la novela, pero no la única-, la pone al cuidado de un pariente, años después se casan y tienen un hijo, Víctor. En este punto de la novela encontramos numerosas descripciones acerca de la infancia del personaje y la devoción que sus padres sentían por él:

With this deep consciousness of what they owed towards the being to which they had given life, added to the active spirit of tenderness that animated both, it may be imagined 
that while during every hour of my infant life I received a lesson of patience, of charity, and of self-control, I was so guided by a silken cord that all seemed but one train of enjoyment to me $(27){ }^{2}$

En esta cita podemos ver una visión alejada, desde un Víctor adulto, de su propia infancia. Con esa distancia, el personaje remarca la fascinación de sus padres por haber creado una vida. Esto se presenta como una anticipación del texto, en tanto Víctor también dará a luz, pero a un ser otro, no humano y sobre el que tendrá sentimientos encontrados. La ternura, paciencia, caridad y amor ilimitado construyen una infancia idealizada, alejada de las preocupaciones del presente de enunciación de Víctor: buscar al monstruo en el Polo y casi morir en el intento.

Otra cuestión a destacar es la mención del autocontrol. La infancia de Víctor responde a la del sujeto neoclásico dominado por la razón y una serie de reglas para conducirse en la sociedad, ese deber ser que se inculca. Tal como sostiene Burdiel (I999): “Así, a diferencia de la gran mayoría de las novelas góticas de su época, con su tendencia hacia el anacronismo histórico y su utilización de elementos mágicos o religiosos, Frankenstein se sitúa claramente en la 'Edad de la Razón”" (57). El personaje de Víctor se encuentra en la encrucijada de un cambio de época. De un pasaje del ser racional al genio creador romántico, que se ve sobre todo en su edad adulta.

Según Paul Ricoeur (2008), en la novela educativa todo gira en torno al despertar del personaje principal: "Es, en primer lugar, la conquista de su madurez la que proporciona la trama de la narración; luego son sus dudas, la confusión, la dificultad para situarse y ordenarse las que rigen cada vez más el rumbo del tipo" (387). Este análisis de Ricoeur nos conduce a pensar en Frankenstein como un Bildungsroman, es decir, un relato en el que se focaliza la formación integral de un individuo representativo, en este caso, el joven burgués y científico. Sin embargo, también encontraremos los relatos de crecimiento y formación de otros personajes. Sumado a esto, cada historia se caracteriza por estar dirigida a un interlocutor concreto: Walton le escribe a su hermana, Frankestein le cuenta su historia a Walton, la criatura habla con su creador.

Por otra parte, el "silken cord" del fragmento citado se puede leer como alegoría de la crianza, de la subordinación a los padres y sus reglas particulares. En esta construcción familiar que hace Shelley se devela el pasaje de la familia feudal a la nuclear, también de esa época. Ya no encontramos al señor feudal ni sus súbditos, sino que en la novela la unidad familiar está conformada a partir del matrimonio y su hijo. En este primer capítulo nos topamos con un elemento que se volverá recurrente: la orfandad. La madre de Víctor es huérfana y su futuro esposo la "adopta” para luego casarse con ella. María

\footnotetext{
${ }^{2}$ Las citas se analizan a partir del idioma original, pero en nota al pie se transcribirán sus traducciones al español: "Con esta profunda conciencia de su deuda con el ser al cual habían dado vida, sumada al activo espíritu de ternura que los animaba a ambos, puede imaginarse que cada hora de mi vida infantil recibí una lección de paciencia, caridad y autocontrol, y estuve guiado por un hilo de seda de modo que todo parecía un tren de goce para mí" (Shelley, 2008: 37).
} 
Negroni (I999) enumera a los diferentes personajes huérfanos que aparecen en la novela y los relaciona con el impulso creativo y su fracaso, así como también con el frío y agua. Este último elemento se asocia con lo materno en tanto representa el líquido amniótico en el vientre. Todos estos elementos caracterizan el modo gótico de Frankenstein. El sentimiento de fascinación de los padres de Víctor por la vida gestada también se relaciona, entonces, con la repetición y la necesidad de engendrar nueva vida o incorporar a un integrante a la familia, con la construcción de un hilo de seda que los una y los ponga al amparo familiar.

La tercera huérfana en presentarse en la novela es Elizabeth, hermana adoptiva de Víctor, que no tiene voz propia, salvo en algunas cartas escritas, pero ya en la edad adulta. Sin embargo, su perspectiva está mayormente mediada por la conciencia de su hermano. El deseo de incorporar una niña a la familia Frankenstein no se resuelve por vía natural:

Among these there was one which attracted my mother far above all the rest. She appeared of a different stock. The four others were dark-eyed, hardy little vagrants; this child was thin and very fair. Her hair was the brightest living gold, and despite the poverty of her clothing, seemed to set a crown of distinction on her head. Her brow was clear and ample, her blue eyes cloudless, and her lips and the moulding of her face so expressive of sensibility and sweetness that none could behold her without looking her as of a distinct species, a being heaven-sent, and bearing a celestial stamp in all her features (28). ${ }^{3}$

La descripción del narrador presenta aquí la visión de la madre sobre Elizabeth y su percepción en su primer contacto. El personaje es caracterizado como un sujeto angelado: pelo dorado, ojos azules, hermosura, dulzura. Su distinción y sensibilidad son la marca celestial que se menciona al final de la cita. Esta es una primera impresión con una base fuertemente anclada en la imagen y la apariencia, elemento que también es fundamental en la niñez monstruosa, en la que nos detendremos en el próximo apartado. Este fragmento se encuentra a tono con el primero. En ambos, Víctor, narrador de los hechos, construye imágenes desprovistas de fealdad, de sufrimiento. Aunque la historia previa de Elizabeth es dura, ya que su padre fallece y ella queda a cargo de una familia pobre, rápidamente es rescatada por los Frankenstein, convirtiéndose en una hija más.

La primera infancia es para Víctor la edad de oro de la vida, donde la pureza del niño junto con una crianza amorosa asegura la felicidad. Esta etapa representa un espacio para la imaginación, lejos de las responsabilidades de la vida adulta (Aguirre Romero, I998). A esta visión completamente idealizada, comienzan a yuxtaponerse otras, a medida que pasa el tiempo y los niños de la familia crecen:

\footnotetext{
3 “Entre ellos una niña llamó la atención de mi madre mucho más que el resto. Parecía de un linaje diferente. Los otros cuatro eran de ojos oscuros y eran pequeños y robustos vagabundos; esta niña era delgada y muy hermosa. Su pelo era del dorado más brillante que existe y, a pesar de la pobreza de sus vestidos, parecía tener un halo de distinción en su cabeza. Su frente descubierta y amplia, sus ojos azules, sus labios y la forma de su cara expresaban tanta sensibilidad y dulzura que nadie podía contemplarla sin verla como un ser diferente, un ser enviado por el cielo y que llevaba un sello celestial en sus rasgos" (38).
} 
While my companion contemplated with a serious and satisfied spirit the magnificent appearances of things, I delighted in investigating their causes. The world was to me a secret which I desired to divine. Curiosity, earnest research to learn the hidden laws of nature, gladness akin to rapture, as they were un folded to me, are among the earliest sensations I can remember (...) No human being could have passed a happier childhood than myself. My parents were possessed by the very spirit of kindness and indulgence (...) My temper was sometimes violent, and my passions vehement; but by some law in my temperature they were turned not towards childish pursuits but to an eager desire to learn, and not to learn all things indiscriminately $\left(3 \mathrm{I}^{-} 33\right){ }^{4}$

Víctor contrapone aquí su personalidad a la de Elizabeth. Ella hace de la contemplación su objetivo principal, se limita a mirar con admiración la naturaleza, pareciera que con cierto respeto. Él, sin embargo, tiene otra actitud, pone en primer plano la curiosidad. El personaje femenino se encuentra en perfecta armonía con la naturaleza, reforzando la construcción de la infancia como edad de oro de la vida. Aguirre Romero (I998) asocia las diferentes edades de la humanidad presentes en las Metamorfosis de Ovidio con las etapas de la vida de los héroes románticos. Si bien el crítico no aborda la novela que estamos trabajando, su perspectiva enriquece nuestro análisis: "La Naturaleza se comporta como una auténtica madre protectora de sus hijos los hombres. Cuando la armonía se rompe, el hombre se vuelve contra la Naturaleza, a la que trata de explotar, y ésta se revuelve contra el hombre" (s/p). La búsqueda incesante que encarna Víctor se desprende de su deseo por conocer más allá de lo permitido. El personaje tiene las inquietudes del hombre del siglo XIX deslumbrado por la ciencia y los avances desmedidos del campo en ese momento. Por otro lado, se configura como un romántico "un rebelde que se yergue, activo y desdeñoso, contra las leyes y los límites que le oprimen, y desafía a la sociedad y a Dios mismo" (Aguiar e Silva, I982: 333). Esta particularidad de Víctor es vista por él mismo como opuesta a la forma de ser de Elizabeth y también a su familia. Si este par conforma el amor, la felicidad, la bondad, Víctor es el hijo díscolo, pasional que se aleja de la edad de oro infantil. A medida que crece - como el Emilio de Rousseau- el deseo por desafiar los límites corrompe al personaje. Distinto es lo que sucede con Elizabeth quien, desde la perspectiva de Víctor, conserva su pureza aun en la adultez. Estas emociones que no responden a lo esperado erosionan la concepción romántica de la infancia presente en la novela, preparando el terreno textual para el quiebre que se propone con el personaje de la criatura. La curiosidad sin límites del joven científico lo llevan a cometer el peor error de su vida: la creación de un ser trastocando las leyes de la naturaleza.

\footnotetext{
4 "Mientras mi compañera contemplaba con un espíritu serio y satisfecho el magnífico aspecto de las cosas, yo me deleitaba investigando sus causas. El mundo era para mí un secreto que yo deseaba adivinar. La curiosidad, el vivo interés por aprender las leyes ocultas de la naturaleza y la alegría cercana al éxtasis, cuando me eran revelados, son las sensaciones más tempranas que puedo recordar. (...) Ningún ser humano puede haber tenido una niñez más feliz que yo. Mis padres estaban como poseídos por el espíritu de la bondad y la indulgencia. (...) Mi carácter era, algunas veces, violento y mis pasiones vehementes; pero por alguna ley que gobernaba mi temperamento no se inclinaba hacia búsquedas infantiles" $(4 \mathrm{O}-4 \mathrm{I})$.
} 


\section{La niñez monstruosa}

En Frankenstein, entonces, no sólo aparece la infancia humana, sino también la del personaje creado por Víctor. Según Amícola (2003) darle la voz a un personaje de estas características es uno de los principales aportes de Mary Shelley: "no ha dudado en hacer escuchar la voz del Otro, aunque ese otro estuviera condenado de antemano a ser monstruoso y su discurso fuera terriblemente desarticulador de los principios de la razón moderna y postmoderna" (68). En la novela no sólo se presenta al personaje monstruoso por su aspecto físico y las acciones que lleva a cabo, sino que se le da la palabra para que pueda expresarse, contar su vida y su perspectiva de los hechos. A diferencia del recuerdo del joven que piensa en su niñez para reconstruir su historia dedicada un oyente que no conoce, en el relato de la criatura, si bien aparece mediado por Víctor, la narración de la infancia es mucho más cercana temporalmente al nacimiento. La criatura cuenta lo sucedido luego de su nacimiento de este modo:

It is with considerable difficulty that I remember the original era of my being; all the events of that period appear confused and indistinct. A strange multiplicity of sensations seized me, and I saw, felt, heard, and smelt at the same time; and it was, indeed, a long time before I learned to distinguish between the operations of my various senses (II8). ${ }^{5}$

Su primer recuerdo no es la bondad paterna sino una sensación de desconcierto, confusión y sentidos abombados. Desde el comienzo de la vida de la criatura hay aprendizaje, tal como sucede con los seres humanos. A este camino de puro aprender va a estar supeditada la supervivencia del monstruo, pero su educación no tendrá que ver con un contexto amoroso, ni con la guía de tutores felizmente ocupados en él, sino con sentimientos de soledad e inquietud. Este despertar a la vida se asemeja a la confusión generalizada de cualquier ser al nacer. Sin embargo, la criatura, rápida y dolorosamente, entiende que la reclusión es el único camino posible para él. Y a partir de ocultarse, escuchar y observar lo que hacen los humanos, aprende. Tal como habíamos visto en el personaje de Elizabeth, el monstruo hace de la percepción el tema principal en su narración. Lo que sus sentidos perciben y su visión de un mundo maravilloso se imponen en un primer momento.

Other lessons were impressed upon me even more deeply. I heard of the difference of sexes, and the birth and growth of children, how the father doted on the smiles of the infant, and the lively sallies of the older child, how all the life and cares of the mother

\footnotetext{
5 "Es muy dificultoso para mí recordar la época inicial de mi existencia. Todos los acontecimientos de ese período aparecen confusos y turbios. Múltiples sensaciones desconocidas se apoderaron de mí, y yo obtuve la capacidad de ver, sentir, oír y oler al mismo tiempo. Y por cierto, pasó mucho tiempo antes de que aprendiera a diferenciar el funcionamiento de mis diversos sentidos" (IO4).
} 
were wrapped up in the precious charge, how the mind of youth expanded and gained knowledge, of brother, sister, and all the various relationships which bind one human being to another in mutual bonds.

But where were my friends and relations? No father had watched my infant days, no mother had blessed me with smiles and caresses; or if they had, all my past life was now a blot, a blind vacancy in which I distinguished nothing. From my earliest remembrance I had been as I then was in height and proportion. I had never yet seen a being resembling me or who claimed any intercourse with me. What was I? The question again recurred, to be answered only with groans $\left(\mathrm{I}_{4} 2-\mathrm{I} 43\right){ }^{6}$

En el primer párrafo encontramos una lista de todo lo que debería suceder en la infancia de un niño o niña desde la perspectiva romántica: todas las acciones se encuentran ancladas fuertemente en la familia. Madre, padre y hermanos determinan la vida del niño, tal y como les sucede a los personajes de Víctor y Elizabeth. Ya en el segundo párrafo, la criatura se pregunta también por qué no obtiene eso él mismo. El monstruo demuestra tener claro qué actitudes se asocian a lo femenino, por ejemplo, en la madre cariñosa, de la que él carece. De la madre se espera que sea el hilo de seda conductor del amor. La criatura es producto de la razón de un hombre, de su experticia, su inteligencia y su osadía, pero no es gestado en el cuerpo y, además, su creador lo abandona. Como hemos mencionado, en la novela hay una gran presencia de personajes huérfanos, como la madre de Víctor y la propia Elizabeth. Para que la infancia se constituya como la edad de oro al que el personaje quiere volver mediante el recuerdo, la presencia de la madre -o alguien que ocupe su lugar, como en el caso de la adopción de Elizabeth, por ejemplo-se vuelve fundamental.

A partir de esta percepción del entorno, el sujeto tiene la posibilidad de preguntarse por su propia identidad. Y para eso el lenguaje es una adquisición fundamental. Es en ese decirse a sí mismo dirigido a Víctor, cuando la criatura demuestra su humanidad, más allá de los hechos terribles que lleva a cabo en la novela. Los rasgos físicos que distinguen a la criatura son humanos, aunque extraordinarios, como sostiene Burdiel (I999: $5^{8)}$. La infancia de la criatura demuestra que el sujeto siempre llega al mundo predispuesto para su edad de oro. Sin embargo, y nuevamente aludimos a Rousseau, son el contexto y la sociedad los que influyen en su desarrollo y lo alejan de la infancia romántica idealizada. Por otra parte, hay en este personaje una formación distinta a la de los analizados en el

\footnotetext{
6 “Otras lecciones dejaron más huella sobre mí. Había oído de la diferencia de sexos, y del nacimiento y crecimiento de los niños; de cómo el padre disfrutaba con las sonrisas del niño y con las adorables sonrisas de su niño u con las adorables salidas del hijo mayor; de cómo toda la vida y cuidados de la madre estaban envueltos en aquella preciosa carga; de cómo la mente joven crece y gana conocimientos; de hermano, la hermana y todas las relaciones que unen un ser humano a otro a través de lazos mutuos. Pero, ¿dónde estaban mis amigos v parientes? Ningún padre había vigilado mi infancia, ninguna madre me había bendecido con sus sonrisas y cuidados, y si lo habían hecho, toda mi vida anterior se había borrado, se había convertido en un vacío en el que no distinguía nada. Incluso en mis más antiguos recuerdos yo había sido siempre como era entonces, tanto en altura como en proporciones. Ni siquiera había visto alguna vez un ser que se me pareciese o que quisiera tener alguna relación conmigo. ¿Qué era yo? La pregunta volvía una y otra vez a mí, pero sólo podía responderla con gruñidos” (I2I).
} 
apartado anterior. La escuela de la criatura es la observación y la comprobación empírica de sus diferencias con los seres humanos, lo que solo genera confusión, dolor y soledad. Como afirma Gadamer (I993), la verdadera experiencia formadora del ser proviene del sufrimiento y el dolor, es decir, que aprender a padecer forma parte de la educación. Sólo la criatura puede dar cuenta de un auténtico padecimiento, humanizándolo, a pesar de que eso desate la violencia sobre el resto de los personajes. En este segundo relato de infancia sucede la verdadera experiencia de formación, que, a su vez, rompe el ciclo del Bildungsroman, ya que el personaje no puede insertarse en la sociedad. En la criatura podemos ver cómo se resquebraja la representación romántica de infancia. Si bien esta ruptura se encarna en un personaje no humano, Otro, que se denomina "criatura" por su origen y aspecto, hemos visto que su relato autobiográfico lo homologa a la niñez humana.

Las representaciones de infancia que se construyen en Frankenstein se anclan en la visión romántica. Sin embargo, se presentan fisuras en ese modo de concebir la primera parte de la vida. Si en la infancia se encuentra el germen de lo que sucederá en la juventud y la adultez, la suerte está echada para los personajes desde el inicio. La historia de vida de Víctor Frankenstein y de su criatura, en constante contraposición y con más puntos en común que distancias, se aleja de la existencia de Elizabeth. Sin embargo, más allá de la niñez color de rosa que presenta Víctor, en su constante pregunta por el universo y su curiosidad eterna, encuentra el sentido de su realidad: estudiar el límite entre la vida y la muerte. En esa búsqueda, gesta una nueva vida. Existe una cierta ironía romántica en lo le que acarrea este nacimiento: el sufrimiento y muerte de todos los seres amados por el protagonista, rompiendo el hilo de seda que vincula a la familia.

Elizabeth, por su parte, compone un personaje femenino idealizado, cuya infancia dista mucho de ser perfecta. Sin embargo, Víctor presenta a una niña angelada, haciendo énfasis en sus rasgos físicos y belleza, más que la crueldad que había sacudido sus primeros años. Elizabeth, a diferencia de Víctor, se contenta con contemplar la naturaleza, maravillada, sin necesidad de ponerla a prueba. La edad de oro de la infancia para el científico es la que comparte con Elizabeth, ese espacio simbólico libre de las preocupaciones que sus propias acciones acarrean sobre él y su familia.

Por último, la infancia monstruosa deja en evidencia que el nacimiento, aunque sea sobrenatural, nos iguala. Sin embargo, la soledad y la falta de amor filial, y especialmente materno, sólo pueden engendrar rencor y violencia desde la misma niñez. En el sufrimiento de Elizabeth y la criatura encontramos la verdadera experiencia. Como destaca Amícola (2003), la voz del Otro es potente y se impone. Y analizar la infancia monstruosa nos ha demostrado que al menos para Mary Shelley, en esa etapa de la vida, y más allá de los caracteres personales, un niño o niña puede sobreponerse a todo si tiene adultos amorosos que lo tutelen.

Walter Benjamin (I989) entiende que la experiencia es individual. Esa experiencia intransferible constituye la máscara tras la cual se encuentran todos los adultos. Desde este enfoque, la niñez y la juventud son etapas en las que la máscara aún no se ha instituido. Las máscaras que Shelley esboza en la novela recuperan las representaciones 
románticas de la infancia a su vez que muestran sus límites. En esta complejidad se imbrican otras fuerzas presentes en la novela como los elementos autobiográfico, el gótico, la novela de formación y el fantástico, que impactan en los modos de construir la infancia propios de este texto. 


\section{Referencias bibliográficas}

- Aguiar e Silvia, V. M. (I982). Teoría de la Literatura. Madrid: Gredos.

- Aguirre Romero, J. (r998, julio). Niño y Poeta. La mitificación de la infancia en el Romanticismo. Espéculo: Revista de Estudios Literarios, núm. 9. Obtenido el o3 de febrero de 2O2I desde https://webs.ucm.es/info/especulo/numerog/ninoroma.html

- Alzate Piedrahita, M. V. (2002, enero). Concepciones e imágenes de infancia. Revista de Ciencias Humanas nro. 28 . Obtenido el 20 de marzo de 2020 desde https://repository. unad.edu.co/bitstream/IO596/4863/I/5I45I7\%2oinfancia.pdf

- Amícola, J. (2003). La batalla de los géneros: novela gótica versus novela de educación. Buenos Aires: Beatriz Viterbo.

- Benjamin, W. (1989). Escritos. La literatura infantil, los niños y los jóvenes. Buenos Aires: Nueva Visión.

- Burdiel, I. (1999). "Frankenstein" o la identidad monstruosa. En Shelley, M. Frankenstein o el moderno Prometeo (pp. 9-ІІз).Madrid: Cátedra.

- Gadamer, H. (г993). Verdad y método. Salamanca: Ediciones Sígueme.

- Gandolfo, E. (20I7) . El libro de los géneros recargado. Buenos Aires: Blatt y ríos.

- Negroni, M. (1999). Frankenstein: el sabor de los climas helados. En Museo negro (pp. I59-I66). Buenos Aires: Norma.

- Ricoeur, P. (2008). Tiempo y narración II. México: Siglo XXI.

- Shelley, M. (2008). Frankenstein. Buenos Aires: Centro Editor de Cultura.

- Shelley, M. (s/d). Frankenstein. Free Books. Obtenido el 20 de marzo de 2020 desde https://www.planetebook.com/free-ebooks/frankenstein.pdf

- Peckam, M. (1962). Beyond the tragic visión: The quest for identity in the nineteenth century. Nueva York: George Braziller. 